\title{
Global fast terminal sliding mode control strategy for permanent magnet synchronous motor based on load torque Luenberger observer
}

\author{
Changlin Zhu' ${ }^{1}$, Qunzhang Tu ${ }^{1 a)}$, Chengming Jiang', Ming Pan ${ }^{1}$, Hao Huang ${ }^{1}$, and Zhiwen Tu${ }^{1}$
}

\begin{abstract}
Aiming at the problems of slow response speed and chattering phenomenon in general sliding mode control of permanent magnet synchronous motor, a global fast terminal sliding mode control strategy is proposed to improve the response speed and the antiinterference ability of the system. A load torque Luenberger observer is designed, and the observed value is fed back to the global fast terminal sliding mode controller of permanent magnet synchronous motor control system in order to reduce the influence of external load disturbance. A permanent magnet synchronous motor experiments platform is built to verify the performance of the proposed control strategy and the effectiveness of the observer. The experimental results show that the load torque Luenberger observer can better observe the actual load torque and track the actual speed of the motor. The global fast terminal sliding mode control strategy improves the response speed of the motor and enhances the robustness of the system.

key words: permanent magnet synchronous motor, global fast terminal sliding mode control, load torque Luenberger observer

Classification: Electron devices, circuits and modules
\end{abstract}

\section{Introduction}

In recent years, electric vehicles have been fully developed. Permanent magnet synchronous motor (PMSM) is widely used in the field of electric vehicles because of its high-power density, high efficiency, and simple structure [1]. However, because PMSM is a nonlinear, multivariable, and strongly coupled control object, the conventional proportional integral differential (PID) control has overshoot, which is difficult to meet the requirements of high control accuracy [2]. Sliding mode control (SMC) has a simple algorithm, insensitive to parameter changes and disturbances, and simple physical implementation. The application of SMC to PMSM speed regulation system has increasingly become a research hotspot of scholars [3-10]. As early as the last century, Utkin A et al. [11] described in detail the design method of SMC in PMSM. A new reaching law is

\footnotetext{
${ }^{1}$ College of Field Engineering, Army Engineering University of PLA, Nanjing 210007, China

a)tqzlhnj@126.com
}

DOI: 10.1587/elex.18.20210348

Received August 19, 2021

Accepted August 31, 2021

Publicized September 07, 2021 proposed in [12], which improves the convergence speed of PMSM system to equilibrium state; A. Kawamura et al. designed the disturbance observer. Through the feedforward compensation of external disturbance, the PMSM has strong robustness and ideal anti-interference ability, and ensures good speed tracking performance [13]. However, due to the discontinuous switching characteristics in the design of conventional SMC, the chattering phenomenon which can increase the system energy consumption and reduce the system stability is caused. In order to suppress the chattering phenomenon, Slotine et al. [14] introduced the concepts of "quasi sliding mode" and "boundary layer" into the design of SMC, which effectively suppressed the chattering phenomenon. Nonetheless, the selection of boundary layer thickness caused the contradiction between the suppression effect and the control effect, which could not be optimized at the same time. W. Gao [15] introduced the concept of reaching law in the design of SMC, and proposed a chattering elimination method. By adjusting the parameters of reaching law, the dynamic quality of sliding mode dynamic arrival process is guaranteed, but chattering will be caused when the parameters are large. Y. B. Sun et al. [16] combined fuzzy control rules with sliding mode variable structure control, proposed fuzzy sliding mode control strategy, and achieved the purpose of suppressing chattering.

Although the above methods suppress the chattering to a certain extent, all of them can not fundamentally solve the chattering problem, which is rooted in the switching term in the conventional SMC [17-22]. Replacing the switching term in SMC with nonlinear function and designing terminal sliding mode control (TSMC) strategy is one of the methods to solve the chattering problem [23]. K. Y. Zhuang et al. [24] designed a terminal sliding mode surface suitable for high-order nonlinear systems, which overcomes the disadvantage of discontinuous derivative of sliding mode surface of conventional SMC. but ordinary terminal sliding mode controller has singularity problem. In order to solve the singularity problem, Y. Feng et al. proposed a nonsingular terminal sliding mode control (NTSMC) 
strategy to solve the singularity problem [25]. However, in order to overcome the disturbance caused by external load and parameter changes, the symbolic function is introduced into the nonsingular terminal sliding mode control, so the chattering problem arises again. J. K. Liu et al. [26] proposed global fast terminal sliding mode control (GFTSMC) for nonlinear systems. Combined with the advantages of traditional SMC and TSMC, by imposing constraints on parameters, the singularity problem is avoided, the speed of system response is improved, and the chattering in sliding mode control is effectively eliminated.

In this paper, a GFTSMC strategy for PMSM is proposed for the scenario of variable load. The GFTSMC algorithm is used to design the motor speed controller, and the load torque Luenberger observer (LTLO) is designed to observe the external load of PMSM in real time, and the observed value is fed back to the global fast terminal sliding mode controller to improve the response speed of PMSM system, The robustness of the system is enhanced.

\section{Mathematical model of PMSM}

When establishing the mathematical model of PMSM, the following processing is carried out [27]: (1) assume that the distribution mode of rotor permanent magnet magnetic field in the breath space is sine wave, and the induced electromotive force in the stator armature winding is sine wave distribution; (2) ignore the iron loss and air gap in the magnetic field; (3) the motor is surface mounted PMSM. The rotor flux oriented control of PMSM with $i_{d}=0$ is adopted to establish the dynamic mathematical model of PMSM in $d-q$ coordinate system:

$$
\left\{\begin{array}{l}
u_{d}=R i_{d}-\omega \psi_{q}+\frac{d \psi_{d}}{d t} \\
u_{q}=R i_{q}+\omega \psi_{d}+\frac{d \psi_{q}}{d t}
\end{array}\right.
$$

Where, $u_{d}$ and $u_{q}$ represent the components of $d$ and $q$ axis of stator voltage respectively, $i_{d}$ and $i_{q}$ represent the components of $d$ and $q$ axis of stator current respectively, $R$ represents the stator resistance, $\omega$ represents the rotor electric angular velocity, $\psi_{d}$ and $\psi_{q}$ represent the components of $d$ and $q$ axis of stator flux respectively. The stator flux linkage equation of PMSM is as following:

$$
\left\{\begin{array}{l}
\psi_{d}=\psi_{f}+L_{d} i_{d} \\
\psi_{q}=L_{q} i_{q}
\end{array}\right.
$$

Where, $\psi_{f}$ is the flux from the rotor permanent magnet turn chain to the stator winding, $L_{d}$ and $L_{q}$ are the inductance of $d-q$ axis respectively. The electromagnetic torque equation of PMSM is as following:

$$
T_{e}=\frac{3}{2} p\left(\psi_{d} i_{q}-\psi_{q} i_{d}\right)
$$

Since the motor is surface mounted PMSM, $L_{d}=L_{q}$, substituting equation (2) into equation (3) the following equation can be obtained:

$$
T_{e}=\frac{3}{2} p \psi_{f} i_{q}
$$

The motion equation of PMSM is as following:

$$
T_{e}-T_{l}-\eta \omega=J \dot{\omega}
$$

Where, $T_{l}$ is the load torque of the motor, $\eta$ is viscous damping, and $J$ is the moment of inertia of the rotor. By substituting equation (4) into equation (5), the following equation can be obtained:

$$
\dot{\omega}=\frac{3 p}{2 J} \psi_{f} i_{q}-\frac{\eta}{J} \omega-\frac{T_{l}}{J}
$$

\section{Design of speed controller}

\subsection{Design of GFTSMC}

A high order single input single output nonlinear system is considered:

$$
\left\{\begin{array}{l}
\dot{x}_{m}=x_{m+1}, m=1,2, \cdots, n-1 \\
\dot{x}_{n}=f(x)+g(x) u
\end{array}\right.
$$

Where, $f(x), g(x)$ are smooth functions in $R^{n}$ field, and $g(x) \neq 0, \quad u \in R^{l}$. A fast sliding mode with recursive structure is represented as [28]:

$$
\left\{\begin{array}{l}
s_{1}=s_{0}+\alpha_{0} s_{0}+\beta_{0} s_{0}^{q_{0} / p_{0}} \\
s_{2}=s_{1}+\alpha_{1} s_{1}+\beta_{1} s_{1}^{q_{1} / p_{1}} \\
\cdots \\
s_{n-1}=s_{n-2}+\alpha_{n-2} s_{n-2}+\beta_{n-2} s_{n-2}^{q_{n-2} / p_{n-2}}
\end{array}\right.
$$

Where, $q_{j} 、 p_{j}\left(q_{j}<p_{j}\right)(j=1,2, \cdots n-2), \alpha_{j}, \beta_{j}>0$ are odd numbers. In order to avoid the singularity problem in the global fast terminal sliding mode, the following conditions must be satisfied [29]:

$$
\frac{q_{j}}{p_{j}}>\frac{n-j-1}{n-j}
$$

The global fast terminal sliding mode control law is designed as following:

$$
u(t)=-\frac{1}{g(x)}\left(\begin{array}{l}
f(x)+\sum_{k=0}^{n-2} \alpha_{k} s_{k}^{(n-k-1)}+ \\
\sum_{k=0}^{n-2} \beta_{k} \frac{d^{n-k-1}}{d t^{n-k-1}} s_{k}^{q_{k} / p_{k}}+\varphi s_{n-1}+\gamma s_{n-1}^{q / p}
\end{array}\right)
$$

Where, $s_{0}=x_{1}, \varphi, \gamma>0 p$ and $q(p>q)$ are positive odd numbers.

Consider that PMSM is a second-order single input single output nonlinear control system, the value of $n$ is 
taken as 2 in this paper. The system state variable of PMSM is expressed as:

$$
\left\{\begin{array}{l}
x_{1}=\theta_{r}-\theta \\
x_{2}=\dot{x}_{1}=\dot{\theta}_{r}-\dot{\theta}=\dot{\theta}_{r}-\omega
\end{array}\right.
$$

Where, $\theta_{r}$ is the given angular displacement, $\theta$ is the actual angular displacement. The derivative of equation (11) can be obtained:

$$
\left\{\begin{array}{l}
\dot{x}_{1}=x_{2} \\
\dot{x}_{2}=\ddot{\theta}_{r}-\dot{\omega}=\ddot{\theta}_{r}-\frac{3 p}{2 J} \psi_{f} i_{q}+\frac{\eta}{J} \omega+\frac{T_{l}}{J}
\end{array}\right.
$$

According to equation (8), the global fast terminal sliding mode of PMSM system is expressed as:

$$
s=\dot{x}_{1}+\alpha x_{1}+\beta x_{1}^{q / p}
$$

In order to avoid the singularity problem in the $s$, according to (9), $q<p<2 q$. The GFTSMC is designed as:

$$
i_{q}=\frac{1.5 J}{p \psi_{f}}\left(\ddot{\theta}_{r}+\frac{\eta \omega+T_{l}}{J}+\alpha x_{2}+\frac{\beta d x_{1}^{q / p}}{d t}+\varphi s+\gamma S{ }^{q / p}\right)
$$

\section{2 stability analysis}

Consider a Lyapunov function:

$$
V=\frac{1}{2} s^{2}
$$

The first order differential of $s$ is obtained:

$$
\dot{s}=\ddot{\theta}_{r}-\frac{3 p}{2 J} \psi_{f} i_{q}+\frac{\eta \omega+T_{l}}{J}+\alpha x_{2}+\frac{\beta d x_{1}^{q / p}}{d t}
$$

Substituting equation (14) into equation (16), it can be obtained that:

$$
\dot{s}=-\varphi s-\gamma s^{q / p}
$$

The first derivative of $V$ is obtained:

$$
\dot{V}=s \dot{s}=-\varphi s^{2}-\gamma s^{(p+q) / p}
$$

Since $p$ and $q$ are positive odd numbers and $(p+q)$ are even numbers, $\dot{V} \leq 0$, According to the Lyapunov stability theorem, the controller is asymptotically stable.

\section{Design of LTLO}

In the actual motor control system, the speed is measurable, but the load torque $T_{l}$ is not so $T_{l}$ is unknown. In the design of speed controller, equation (14) contains $T_{l}$. Therefore, it is necessary to design a load torque observer to feed back the observed values of $T_{l}$ to the speed controller. The state variable, input value, and output value of LTLO are selected as following:

$$
\boldsymbol{x}=\left[\begin{array}{l}
\omega \\
T_{l}
\end{array}\right], u=T_{e}, y=\omega
$$

The general form of state space variables is as following:
$\left\{\begin{array}{l}\dot{\boldsymbol{x}}=\boldsymbol{A} x+\boldsymbol{B} u \\ y=\boldsymbol{C} x+\boldsymbol{D} u\end{array}\right.$

Where, $\boldsymbol{A}, \boldsymbol{B}, \boldsymbol{C}$, and $\boldsymbol{D}$ are coefficient matrices, which depend on the parameters of PMSM. In this paper, when the control frequency is very high and the sampling period is very small, the load torque is a constant value in a sampling period. By changing equation (20) to the state space expression, it can be obtained that:

$$
\left[\begin{array}{c}
\dot{\omega} \\
\dot{T}_{l}
\end{array}\right]=\left[\begin{array}{cc}
\frac{-\eta}{J} & \frac{-1}{J} \\
0 & 0
\end{array}\right]\left[\begin{array}{l}
\omega \\
T_{l}
\end{array}\right]+\left[\begin{array}{c}
\frac{1}{J} \\
0
\end{array}\right] T_{e}, y=\left[\begin{array}{ll}
1 & 0
\end{array}\right]\left[\begin{array}{c}
\omega \\
T_{l}
\end{array}\right]
$$

The LTLO is designed as following:

$$
\left\{\begin{array}{l}
\dot{\hat{\boldsymbol{x}}}=\boldsymbol{A} \hat{x}+\boldsymbol{B} u+\boldsymbol{L}(y-\hat{y}) \\
\hat{y}=\boldsymbol{C} \hat{x}
\end{array}\right.
$$

Where, $\boldsymbol{L}$ is a coefficient matrix, and:

$$
\boldsymbol{L}=\left[\begin{array}{l}
L_{1} \\
L_{2}
\end{array}\right], \boldsymbol{A}=\left[\begin{array}{cc}
\frac{-\eta}{J}-L_{1} & \frac{-1}{J} \\
-L_{2} & 0
\end{array}\right], \boldsymbol{B}=\left[\begin{array}{c}
\frac{1}{J} \\
0
\end{array}\right], \boldsymbol{C}=\left[\begin{array}{ll}
1 & 0
\end{array}\right]
$$

Substituting equations (19) and (23) into equation (22), the following results can be obtained:

$$
\left\{\begin{array}{l}
\dot{\hat{\omega}}=\frac{1}{J}\left(T_{e}-\hat{T}_{l}-\eta \hat{\omega}+J L_{1}(\omega-\hat{\omega})\right) \\
\dot{\hat{T}}_{l}=L_{2}(\omega-\hat{\omega})
\end{array}\right.
$$

To make the observed load torque approach the real value, another constraint is that the eigenvalue of $\boldsymbol{A}-\boldsymbol{L} \boldsymbol{C}$ matrix is less than 0 [30]. The eigenvalues of $\boldsymbol{A}-\boldsymbol{L} \boldsymbol{C}$ matrix are obtained:

$$
\left|\lambda \boldsymbol{I}-\left[\begin{array}{cc}
\frac{-\eta}{J}-L_{1} & \frac{-1}{J} \\
-L_{2} & 0
\end{array}\right]\right|=0
$$

Where, $\boldsymbol{I}$ is the unit matrix. The equation (25) is converted into the following form:

$$
\lambda^{2}+\left(\frac{\eta}{J}+L_{1}\right) \lambda-\frac{L_{2}}{J}=0
$$

Set the value of the eigenvalue $\lambda$ be $a_{1}, a_{2}\left(a_{1}<0, a_{2}<0\right)$, and the following result can be obtained:

$$
\lambda^{2}-\left(a_{1}+a_{2}\right) \lambda+a_{1} a_{2}=0
$$

By comparing equations (26) and (27), the following equation can be obtained:

$$
\left\{\begin{array}{l}
L_{1}=-\left(a_{1}+a_{2}+\frac{\eta}{J}\right) \\
L_{2}=-\left(a_{1} a_{2} J\right)
\end{array}\right.
$$

By changing the values of $a_{1}$ and $a_{2}$, the speed of the observed load torque value approaching the real value is adjusted. Substituting $\widehat{T}_{l}$ for $T_{l}$ in equation (14) to obtain:

$i_{q}=\frac{1.5 J}{p \psi_{f}}\left(\ddot{\theta}_{r}+\frac{\eta \omega+\hat{T}_{l}}{J}+\alpha x_{2}+\frac{\beta d x_{1}^{q / p}}{d t}+\varphi s+\gamma S^{q / p}\right)$ 


\section{Experiments}

In order to verify the effectiveness of the GFTSMC strategy and the accuracy of the LTLO proposed in this paper, an experimental platform of PMSM control system is built, as shown in Fig.1. The experimental platform is mainly composed of $\mathrm{PC}$, real-time simulator, controller, PMSM, loading motor, torque and speed sensor, and oscilloscope. The parameters of PMSM are shown in Table 1, and the control structure diagram of the system is shown in Fig.2.

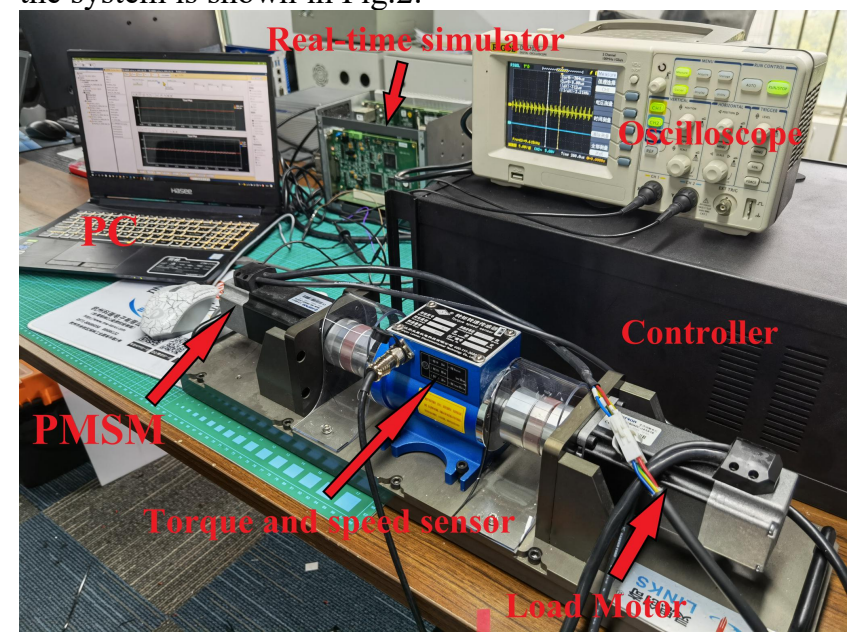

Fig. 1 Experiments platform.

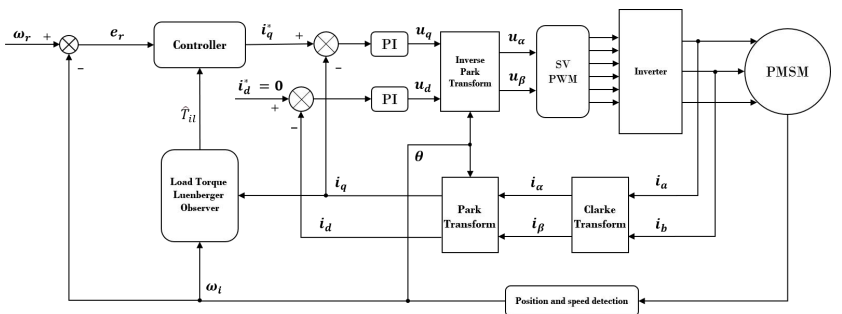

Fig. 2 PMSM control system block diagram.

Table 1 Parameters of PMSM

\begin{tabular}{l|l}
\hline$L_{d}$ & $0.835 \mathrm{mH}$ \\
\hline$L_{q}$ & $0.835 \mathrm{mH}$ \\
\hline$\psi_{f}$ & $0.175 \mathrm{~Wb}$ \\
\hline$R$ & $2.875 \Omega$ \\
\hline$J$ & $0.003 \mathrm{Kg} \cdot \mathrm{m}^{2}$ \\
\hline$\eta$ & $0.008 \mathrm{~N} \cdot \mathrm{m} \cdot \mathrm{s}$ \\
\hline$p$ & 4 \\
\hline
\end{tabular}

The initial speed of the motor is given as $600 \mathrm{r} / \mathrm{min}$. When the system reaches the steady state, the motor receives an external load of $20 \mathrm{~N} \cdot \mathrm{m}$ at $2 \mathrm{~s}$ and unloaded at 3s. Fig.3 is the curve of actual speed and the speed observed by LTLO. It can be seen from Fig. 3 that the observed speed can better track the actual speed.

Fig.4 shows the actual value and observed value of load torque during sudden load increase and sudden load discharge during stable operation of the motor. It can be seen from the Fig. 4 that when the load changes suddenly, the observed value of load torque can better track the actual value of load torque.

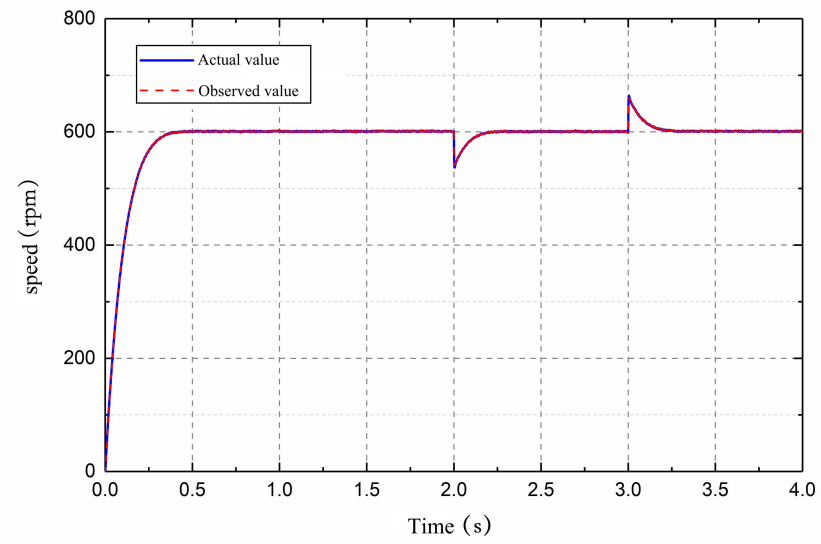

Fig.3 Curve of actual speed and observed speed

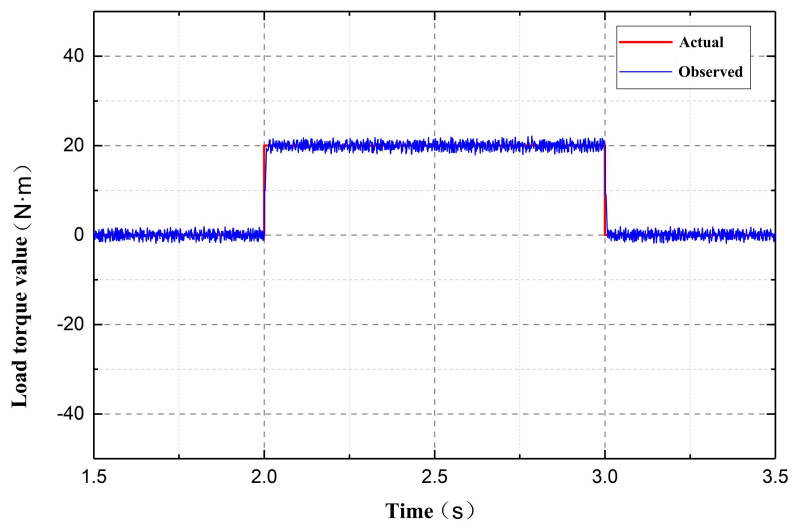

Fig.4 Curve of actual value and observed value of sudden change load

Fig.5 shows the curve of actual value and observed value of gradual load. Given the initial load torque of $10 \mathrm{~N} \cdot \mathrm{m}$, the load starts to increase at a uniform speed at $1.5 \mathrm{~s}$ and unloaded when it increases to $20 \mathrm{~N} \cdot \mathrm{m}$ at $5 \mathrm{~s}$. It can be seen from Fig. $3 \sim 5$ that whether it is sudden load or gradual load, the LTLO can better track the actual speed and accurately estimate the value of load torque.

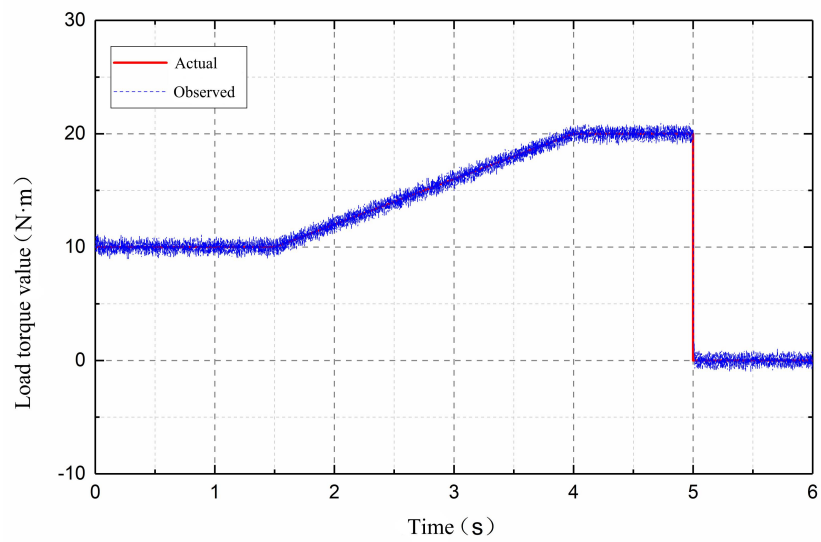

Fig.5 Curve of actual value and observed value of gradual load 
Fig.6 shows the speed curve of SMC strategy and GFTSMC strategy when the motor is started without load. It can be seen from Fig. 6 that the time required for the motor with SMC strategy to reach the steady state is $0.75 \mathrm{~s}$, while the time required for the motor with GFTSMC strategy to reach the steady state is only $0.4 \mathrm{~s}$, and the response time is reduced by $46.7 \%$. The experimental results show that the response speed of GFTSMC strategy is better than that of SMC strategy.

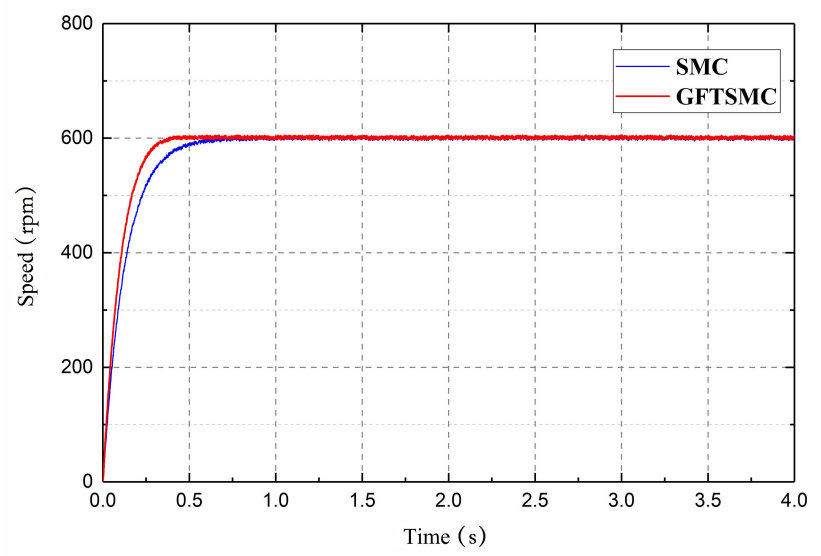

Fig.6 No load starting speed curve of motor

Fig.7 shows the motor speed curve of suddenly increase a load of $20 \mathrm{~N} \cdot \mathrm{m}$ at $2.0 \mathrm{~s}$ and removed at $3.0 \mathrm{~s}$ after the motor runs stably at the speed of $600 \mathrm{r} / \mathrm{min}$. It can be seen from Fig. 7 that the speed fluctuation value of the motor with SMC strategy is about $80 \mathrm{r} / \mathrm{min}$, and the speed of the motor with GFTSMC strategy fluctuates about $60 \mathrm{r} / \mathrm{min}$, and the time to reach the steady state again is about $0.25 \mathrm{~s}$. The speed fluctuation value is reduced by $20 \mathrm{r} / \mathrm{min}$, and it takes less time for the motor with GFTSMC strategy to return to stable state.

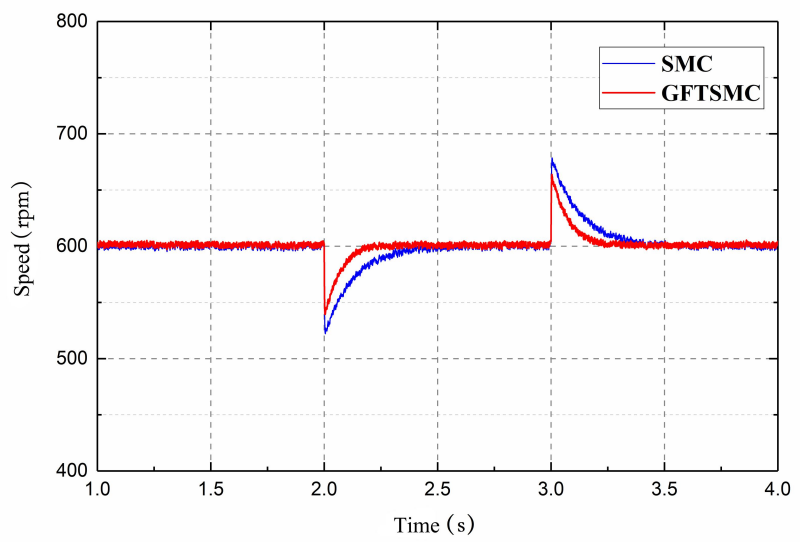

Fig.7 Speed curve of motor with sudden change load

Fig. 8 shows the speed curve of the motor when an $800 \mathrm{r} / \mathrm{min}$ command is given to the motor at $2 \mathrm{~s}$ after the motor runs stably at the speed of $600 \mathrm{r} / \mathrm{min}$. It can be seen from Fig.8 that after giving the command, the time required for the motor with GFTSMC strategy to accelerate from $600 \mathrm{r} / \mathrm{min}$ to $800 \mathrm{r} / \mathrm{min}$ is $12 \mathrm{~ms}$, while the time required for the motor with SMC strategy to accelerate from $600 \mathrm{r} / \mathrm{min}$ to $800 \mathrm{r} / \mathrm{min}$ is $18 \mathrm{~ms}$. Fig. 9 shows the speed curve of the motor when a command of $600 \mathrm{r} / \mathrm{min}$ is given to the motor at $2 \mathrm{~s}$ after the motor runs stably at the speed of $800 \mathrm{r} / \mathrm{min}$. It can be seen from Fig.9 that the time required for the motor with SMC strategy to decelerate from $800 \mathrm{r} / \mathrm{min}$ to $600 \mathrm{r} / \mathrm{min}$ is $19 \mathrm{~ms}$, while the time required for the motor with SMC strategy to decelerate from $800 \mathrm{r} / \mathrm{min}$ to $600 \mathrm{r} / \mathrm{min}$ is $10 \mathrm{~ms}$. As can be seen from Fig.8 and Fig.9, compared with SMC strategy, the motor adopting GFTSMC strategy has shorter response time for variable speed.

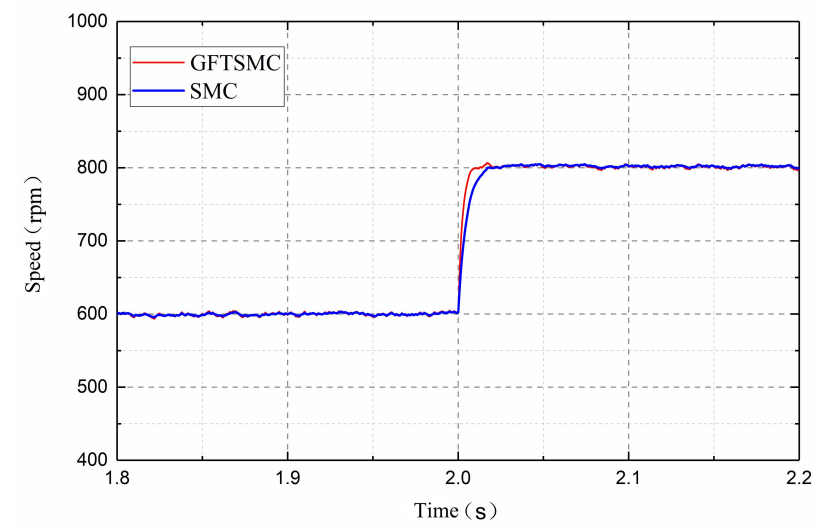

Fig.8 Speed curve of motor speed increase

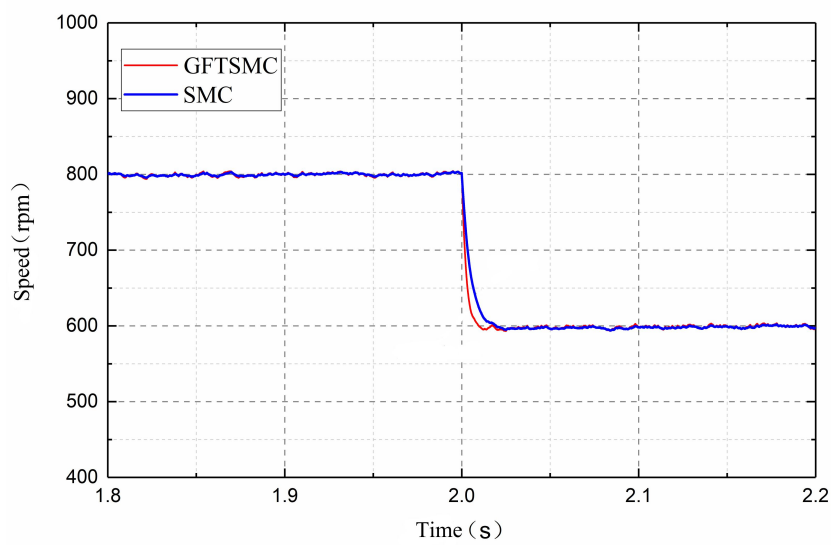

Fig.9 Speed curve of motor speed reduction

Table 2 shows the performance comparison of two different control strategies at startup, sudden load and variable speed. The experimental results show that GFTSMC strategy is better than SMC strategy in response speed and anti-interference ability.

\begin{tabular}{l|l|l}
\multicolumn{3}{c}{ Table 2 Performance comparison between SMC and GFTSMC. } \\
\hline & SMC & GFTSMC \\
\hline Starting time & $0.75 \mathrm{~S}$ & $0.4 \mathrm{~S}$ \\
\hline Sudden load speed fluctuation & $80 \mathrm{r} / \mathrm{min}$ & $60 \mathrm{r} / \mathrm{min}$ \\
\hline Accelerated response time & $18 \mathrm{~ms}$ & $12 \mathrm{~ms}$ \\
\hline Deceleration response time & $19 \mathrm{~ms}$ & $10 \mathrm{~ms}$ \\
\hline
\end{tabular}




\section{Conclusion}

Based on the LTLO, a GFTSMC strategy for PMSM is proposed. The concept of fast arrival and terminal factor are introduced in the design of speed controller, the switching term is cancelled and the chattering phenomenon is eliminated. The LTLO is used to track the speed in real time and observe the external load, and the observed value of load torque is fed back to the global fast terminal sliding mode controller. The experimental results show that the LTLO can better track the actual speed and observe the external load. The GFTSMC strategy based on LTLO can effectively improve the response speed and the anti-interference ability of the PMSM system, and enhance the robustness of the system.

\section{Acknowledgments}

Your acknowledgements to co-workers and financial sponsors are placed here.

\section{References}

[1] LI. W. Y: "Application of PMSM control in electric vehicle," Internal Combustion Engine \& Parts 298 (2019) 51-52.

[2] JIN. P. F, et al.: "Sliding Mode Control of Permanent Magnet Synchronous Motor Based on Load Torque Observer," Small \& Special Electrical Machines 46 (2018) 62-24.

[3] ZHANG. X. G, et al.: "Sliding Mode Control of PMSM Based on a Novel Load Torque Sliding Mode Observer," Proceedings of the CSEE 32 (2012) 111-116.

[4] W. Xu, et al.: "Improved Continuous Fast Terminal Sliding Mode Control With Extended State Observer for Speed Regulation of PMSM Drive System," IEEE Transactions on Vehicular Technology 68 (2019) 10465-1047.

[5] Sun. Z. H, et al.: "Research on the Steady Precision of Sliding Mode Control of a Class of Nonlinear Systems," 2006 6th World Congress on Intelligent Control and Automation, Dalian, (2006) 1039-1043.

[6] L. Saihi, et al.: "A robust sensorless SMC of PMSM based on sliding mode observer and extended Kalman filter," 2015 4th International Conference on Electrical Engineering, Boumerdes (2015) pp. 1-4.

[7] K. Zhao: "Robust Model-Free Nonsingular Terminal Sliding Mode Control for PMSM Demagnetization Fault," IEEE Access 7 (2019). 15737-15748.

[8] Q. Hou, et al.: "Composite Super-twisting Sliding Mode Control Design for PMSM Speed Regulation Problem Based on a Novel Disturbance Observer," IEEE Transactions on Energy Conversion, 2020.

[9] L. Xiang, et al.: "Global Fast Terminal Sliding Mode Control System for Permanent Magnet Synchronous Motor Drive Under Disturbances," 2018 37th Chinese Control Conference, Wuhan, (2018) 3092-3095.

[10] Li S, et al.: "Design and Implementation of Terminal Sliding Mode Control Method for PMSM Speed Regulation System," IEEE Transactions on Industrial Informatics 9 (2013) 1879-1891.

[11] Utkin A, et al.: Sliding Mode Control in Electromechanical Systems (London: Taylor \& Trancis) 1999.

[12] WANG. Y. Q, et al.: "A New Reaching Law for Anti- disturbance Sliding-mode Control of PMSM Speed Regulation System," IEEE Transactions on Power Electronics 35 (2020) 4117-4126.

[13] Kawamura A, et al.: "Chattering Reduction of Disturbance Observer Based Sliding Mode Control," IEE Transactions on Industry Applications, 30 (1994) 456-461.

[14] Slotine J J, and Satry S S: "Tracking Control of Nonlinear Systems Using Sliding Surfaces with Application to Robot Manipulator," International Journal of Control 38(1983): 465-492.

[15] GAO W. B: Theory and Design Method of Variable Structure Control (Beijing, Science Press, 1996).

[16] SUN Y. B, et al.: "Sliding Mode Variable Structure Control of AC Linear Servo System Based on Fuzzy Self-learning," Transactions of China Electrotechnical Society 26 (2000) 136-139.

[17] Yang, J., et al. "Continuous nonsingular terminal sliding mode control for systems with mismatched disturbances," Automatica 49 (2013) 2287-2291.

[18] Tabatabaee-Nasab, et al.: "Nanopositioning control of an electrostatic MEMS actuator: adaptive terminal sliding mode control approach," Nonlinear Dynamics 3 (2021) 1-13.

[19] Fei, J, and Y. Chen: "Dynamic Terminal Sliding-Mode Control for Single-Phase Active Power Filter Using New Feedback Recurrent Neural Network," IEEE Transactions on Power Electronics 99 (2020) 1-1.

[20] Jain, A, and R Saravanakumar: "Intelligent Proportional Integral Terminal Sliding Mode Control for variable speed standalone wind energy conversion system," Environmental Progress \& Sustainable Energy (2020).

[21] Hou, H, et al. "Finite-Time Continuous Terminal Sliding Mode Control of Servo Motor Systems," IEEE Transactions on Industrial Electronics 67 (2019) 1-1.

[22] Zhu, W. L, et al.: "Design and Adaptive Terminal Sliding Mode Control of a Fast Tool Servo System for Diamond Machining of Freeform Surfaces." IEEE Transactions on Industrial Electronics 66 (2019) 4912-4922.

[23] Yu. X. H, and Man. Z. H: "Model Reference Adaptive Control Systems with Terminal Sliding Modes," International Journal of Control 64 (1996) 1165-1176.

[24] ZHUANG. K. Y, et al.: “Terminal Sliding Mode Control for Higher Order Nonlinear Systems," Journal of Zhejiang University 36 (2002) 482-485.

[25] Feng. Y, et al.: "Non-singular Terminal Sliding Mode Control of Rigid Manipulators," Automatica 28 (2002) 2159-2167.

[26] LIU. J. K, and SUN. F. C: "A Novel Dynamic Terminal Sliding Mode Control of Uncertain Nonlinear Systems," Journal of Control Theory and Applications 5 (2007) 189-193.

[27] C. Zhu, et al.: "A Cross Coupling Control Strategy for DualMotor Speed Synchronous System Based on Second Order Global Fast Terminal Sliding Mode Control," IEEE Access 8 (2020) 217967-217976.

[28] S. H. Yu, et al.: "Robust global terminal sliding mode control of SISO nonlinear uncertain systems," Proceedings of the 39th IEEE Conference on Decision and Control, Sydney, NSW (2000) 2198-2203

[29] X. H. Yu, and Z. H. Man: "Fast terminal sliding-mode control design for nonlinear dynamical systems," IEEE Transactions on Circuits and Systems I: Fundamental Theory and Applications 49 (2002) 261-264.

[30] Z. LI, et al.: "Sliding-mode Variable Structure Control With Integral Action for Permanent Magnet Synchronous Motor," Proceedings of the CSEE 34 (2014) 431-437. 